\title{
NUMERICAL APPROACH TO PILE LOAD TEST USING 3D FINITE ELEMENT METHOD
}

Despite the various design approaches, the design of the pile foundations is still to be verified by the in-situ load tests to check the design stage assumptions. This paper presents the results of the study aimed at the soil properties and interaction between piles and soil. Calibration of the numerical model is based on the in-situ pile load test. It represents the case study, how variation of soil characteristics acting in interaction with pile and numerical technics can attain the coinciding results with tested outputs. Moreover, this study is contribution to the effort of designing the pile foundations more accurately with limiting occurrence of potential risks.

Keywords: Pile test, displacement piles, 3D FEM, pile interaction

\section{Introduction}

Confirmation of the pile design by the in-situ tests is a common approach to achieve safe and economic design. The static pile load test is the best method of verifying the bearing capacity of a pile [1]. Mechanisms involved in pressing or pulling of the pile are complicated to describe by the analytical methods. Difference between analytical solutions and real state is represented by the empirical coefficients [2]. On the other hand, numerical modelling allows taking into account the boundary conditions and factors, such as limit settlement of the pile, shear surface propagation around the pile and stress distribution around the pile bottom. However, numerical modelling places more demands on the quality and volume of input data. Accurate model of soil-pile interaction and appropriate soil parameters [3], [4] are the goals of the numerical modelling. The data were optimized through the model calibration until numerical model results reached the outputs of the pile load test.

\section{Static pile load test}

Static pile load test realized on a single massive circular pile offered a basic set of results such as settlement and corresponding load, which were used as a comparable output for numerical model. Static load test carried out on the vertically loaded bored pile [5], with diameter $880 \mathrm{~mm}$ and $5.5 \mathrm{~m}$ length, made by classical method with casing support. The pile is a part of bearing system of a new production hall. The maximum vertical force was set to $870 \mathrm{kN}$ according to the design load determined by the calculation. The pile load test was arranged to measure the ultimate limit state.

Geological profile was explored by the dynamic penetration test (DP), which is suitable in case of deep foundation, especially in case of piles. Penetration of the rod is similar to the pressing of the pile, [6]. For the reason of possible occurrence of large boulders in the top layer consisting of antropogenous soils, a dynamic test method was chosen with weight of the hammer $50 \mathrm{~kg}$. Determined soil properties were verified by the macroscopic evaluation of the borehole core [7], [8].

\section{Numerical model}

Numerical modelling was performed by software Plaxis 3D Foundation using finite element 3D code, (Fig. 1). Numerical model data were taken by the geological survey [7] and had been required a set of soil parameters used by Mohr-Coulomb material model (Table 1.). For the concrete pile material, a linear elastic non-porous model was chosen with unit weight $24 \mathrm{kN} . \mathrm{m}^{-3}$, reference modulus of elasticity $E_{\text {ref }}=31 \mathrm{GPa}$ and Poisson's ratio $v=0.17$

The first step of model series was used to determine the appropriate value of reduction factor $R_{\text {inter }}$ as the parameter of soilpile interaction [1]. Reduction factors, as well as drain conditions were varied. Only undrained conditions (soil fully saturated in terms of short-term condition) with effective shear strength parameters and reduction factor $R_{\text {inter }}=1.0$ were able to achieve closest results in the final settlement of pile head in comparison to test data (Fig. 2). This first approach using only data from

\footnotetext{
* Marian Drusa, Jozef Vlcek

Department of Geotechnics, Faculty of Civil Engineering, University of Zilina, Slovakia

E-mail: drusa@fstav.uniza.sk
} 

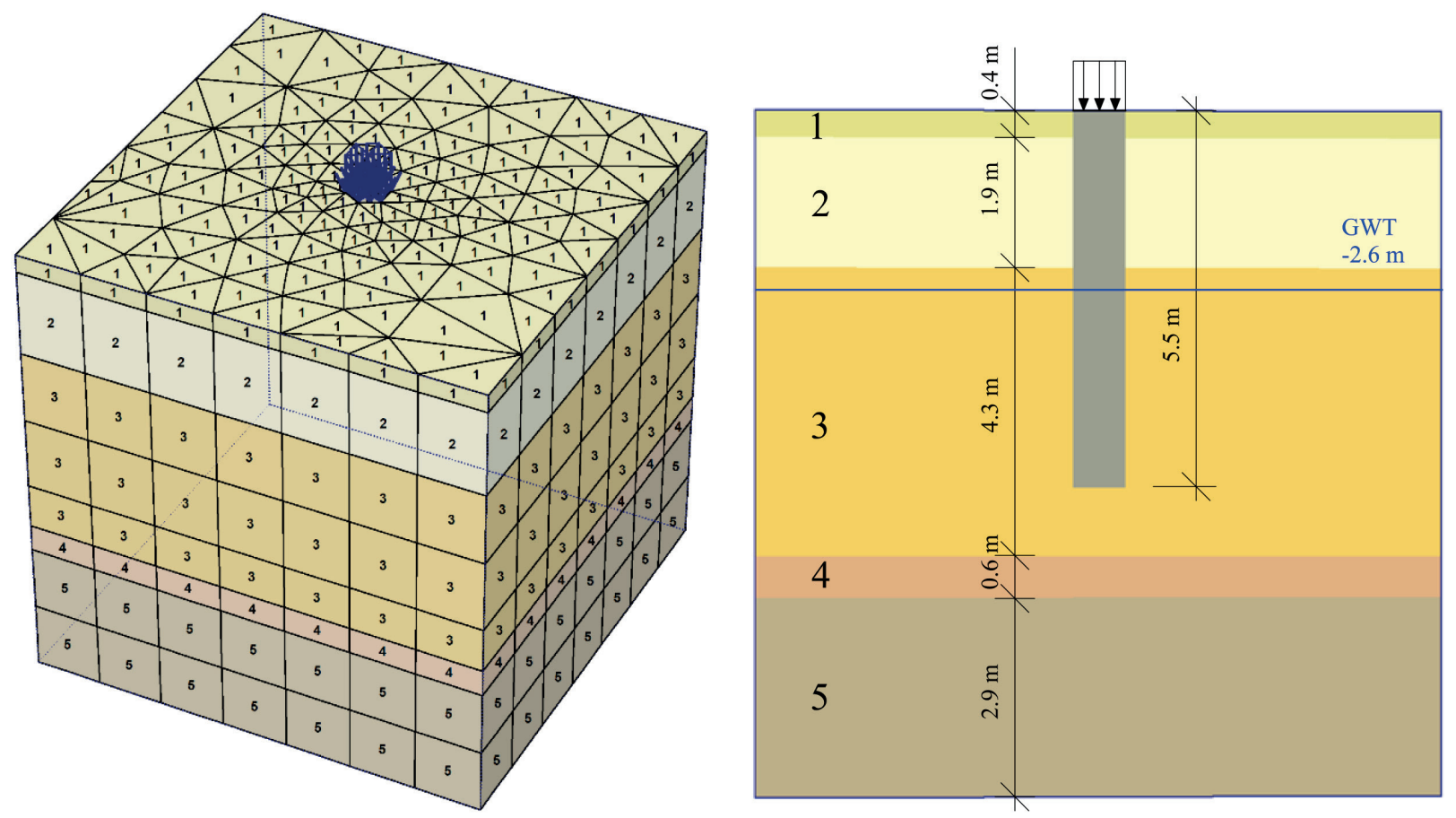

Fig. 1 Numerical model of the tested pile - overall view (left), profile of the model (right)

Soil characteristics for Mohr-Coulomb model

Table 1.

\begin{tabular}{|c|c|c|c|c|c|c|}
\hline \multicolumn{2}{|c|}{$\begin{array}{l}\text { Mohr-Coulomb } \\
\quad \text { model }\end{array}$} & $\begin{array}{c}1 \\
\text { F4 }=\text { CS } \\
\text { firm }\end{array}$ & $\begin{array}{c}2 \\
\text { F4 }=\text { CS } \\
\text { stiff }\end{array}$ & $\begin{array}{c}3 \\
\mathrm{~S} 5=\mathrm{SC} \\
\text { medium }\end{array}$ & $\begin{array}{c}4 \\
\text { S5 }=\text { SC } \\
\text { loose }\end{array}$ & $\begin{array}{c}5 \\
\text { S5 }=\mathrm{SC} \\
\text { medium }\end{array}$ \\
\hline \multicolumn{2}{|c|}{ Type } & Un/Drained & Un/Drained & Un/Drained & Un/Drained & Un/Drained \\
\hline$\gamma_{\text {unsat }}$ & $\left(\mathrm{kN} / \mathrm{m}^{3}\right)$ & 18.5 & 18.5 & 18.5 & 18.0 & 18.5 \\
\hline$\gamma_{\text {sat }}$ & $\left(\mathrm{kN} / \mathrm{m}^{3}\right)$ & 19.0 & 19.0 & 19.5 & 19.0 & 19.5 \\
\hline$E_{\text {ref }}$ & $\left(\mathrm{kN} / \mathrm{m}^{2}\right)$ & 11700 & 25800 & 23000 & 7500 & 28300 \\
\hline$v$ & $(-)$ & 0.35 & 0.35 & 0.35 & 0.35 & 0.35 \\
\hline$c_{r e f}$ & $\left(\mathrm{kN} / \mathrm{m}^{2}\right)$ & 18 & 44 & 5 & 3 & 7 \\
\hline$\varphi$ & $\left({ }^{\circ}\right)$ & 24 & 27 & 26 & 24 & 28 \\
\hline$\psi$ & $\left({ }^{\circ}\right)$ & 0 & 0 & 0 & 0 & 0 \\
\hline$R_{\text {inter. }}$ & $(-)$ & $0.7-1.0$ & $0.7-1.0$ & $0.7-1.0$ & $0.7-1.0$ & $0.7-1.0$ \\
\hline
\end{tabular}

geological survey brought final vertical settlement $5.17 \mathrm{~mm}$, which correlates with experimental settlement of $3.14 \mathrm{~mm}$ obtained from the pile load test [5].

A model simulating the loading process during the pile load test was created based on the results of first approach. Each loading stage was chosen according to the load test protocol (Fig. 3).

In order to achieve the expected results, it is necessary to change the properties of soil below the pile bottom. The soil properties indicate an increase of density and other parameters such as deformation modulus, angle of internal friction and cohesion. This is caused by the compression of the soil under the pile during the test. Along with this, bearing capacity of the movable "floating" pile strongly depends on the bearing capacity of the pile toe. To examine the influence of the modulus and shear strength properties on the overall settlement of the pile, a sensitivity analysis was performed. Chosen parameters were varied in certain steps and an overall settlement was determined for each step, (Fig. 4, 5 and 6). Variation of the values was applied only for layer of clayey sand (cluster No. 3), because the pile toe and main part of the pile body was situated in this soil layer. 
Range, in which the values were changed, was set according to the normalized soil properties from large compilation of in-situ tests.

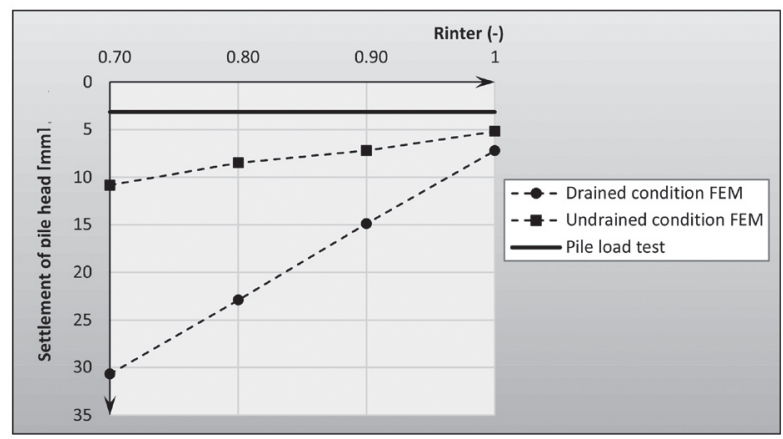

Fig. 2 Settlement of the pile head from FEM analysis and load test

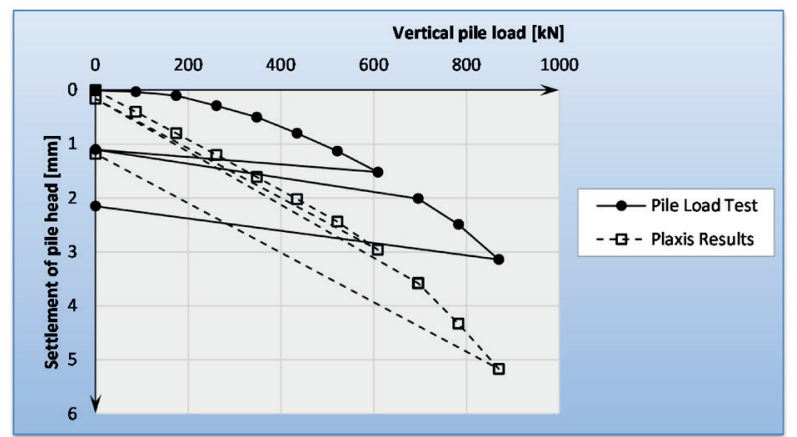

Fig. 3 Work diagram for pile load test and numerical model

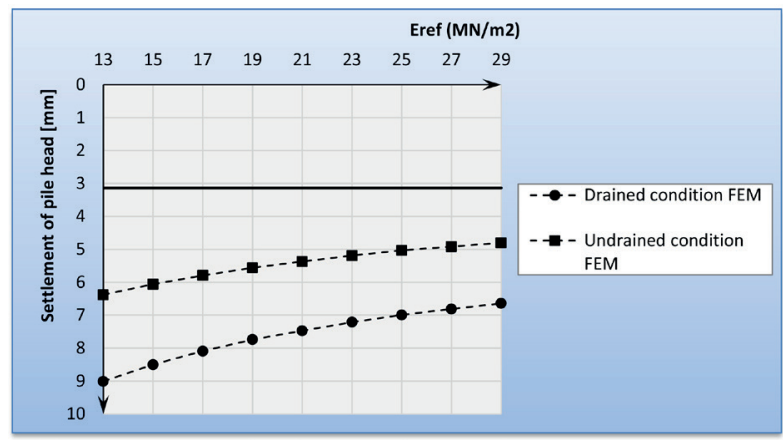

Fig. 4 Influence of the change of modulus on the pile head settlement

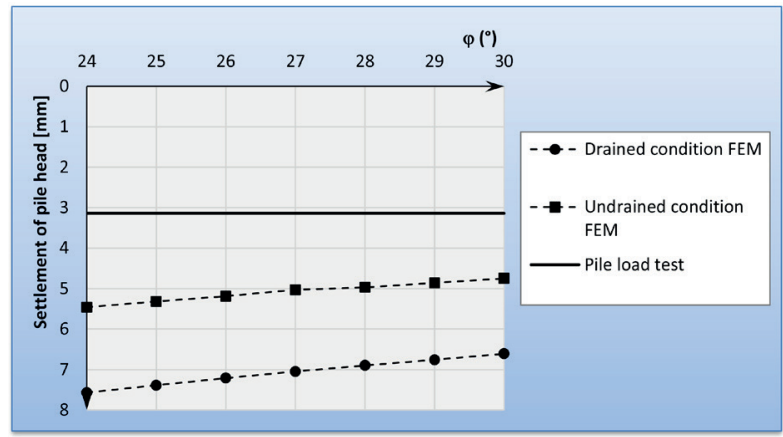

Fig. 5 Influence of the change of internal friction angle on the pile head settlement

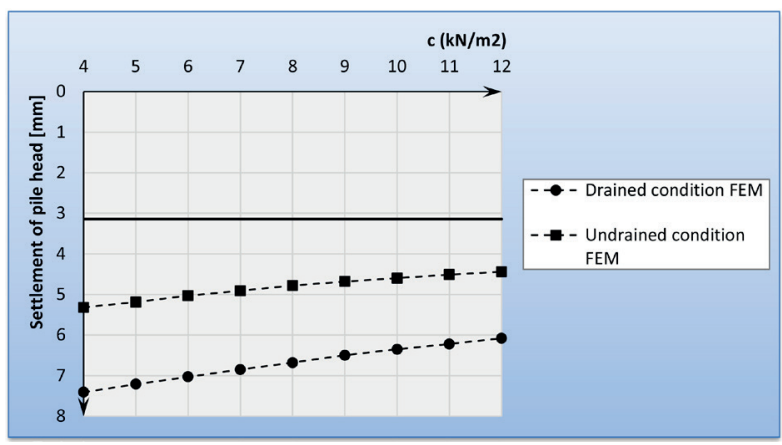

Fig. 6 Influence of the change of cohesion on the pile head settlement

Change of the values of modulus influences the settlement, but only if a wide range of values is taken into account. Within the small range, the difference in the settlement is negligible. (Fig. 4). Different shear strength parameters cause small variations in overall pile head settlement (Fig. 5 and 6). However, change of cohesion brings the results closer to the real measured data.

It should be noted that the use of Mohr-Coulomb material model leads to strictly linear results of settlement development and quite-constant difference between drained and undrained conditions in the particular graphs [9]. This is caused by the linear definition of Mohr-Coulomb material model.

\section{Results of the modelling}

Mentioned analysis is a contribution to the pile design in terms of second limit state considering practical restrictions in input data from the geological survey. Lack of sufficient data sets for soil environment usually restricts the selection

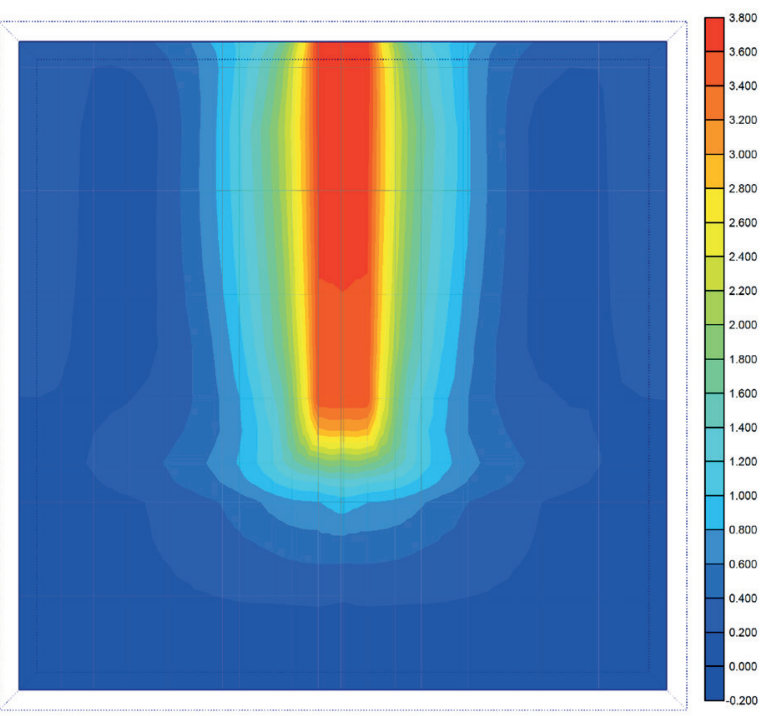

Fig. 7 Overall displacements in the numerical model in $\mathrm{mm}$ 
of appropriate material model to Mohr-Coulomb model. Only in-situ tests were adopted as a basis for numerical model. The results of the modelling indicate that even small improvements in calculation procedure produce outputs with sufficient accuracy in comparison to the measured data.

Variation of selected parameters does not considerably affect the overall settlement, However, using a maximum values of properties for clayey sand layer from sensitivity analysis $\left(E_{\text {ref }}=\right.$ $\left.29 \mathrm{MN} / \mathrm{m}^{2}, \phi=30^{\circ}, c=12 \mathrm{kN} / \mathrm{m}^{2}\right)$ led to pile head settlement of $3.73 \mathrm{~mm}$, which is only $19 \%$ deviation from the measured value of $3.14 \mathrm{~mm}$ (Fig. 7). This reverse calculation procedure determines only assumed parameters of the soil near the pile toe. In order to verify the effect of soil improvement due to the pile settlement, compaction and lateral spreading, it is necessary to perform additional in-situ tests and tests with taken samples.

In the case of additional laboratory tests, using of advanced material models such as Hardening soil model or Soft soil creep model can provide more realistic results and predictions.

\section{Conclusions}

Analysis discussed in this paper represents the contribution to the design of piled foundations in terms of second limit state and overall stability. Settlement of the pile is only an auxiliary value at the pile load test, which checks the bearing capacity of the pile, thus first limit state. This study showed that utilization of undemanding material model and appropriate terrain surveying method can bring similarly accurate results for pile foundation design. Mohr-Coulomb model does not place high demands on input data, which provides an opportunity for practical and economical design of pile foundation. Use of advanced material model requires wider range of input data from terrain sampling and related laboratory tests [9] and [10]. Additional data are more time-consuming and less cost-effective, but usually geotechnical survey is only a minor part of the overall budget of the project. Therefore, basic material models, such as Mohr-Coulomb model, are still capable of providing suitable engineering output. Despite these results, another research in the field of data collection for advanced material models and numerical models calibration is necessary [11]. The research should consider variable geological conditions and numerous structure and load scheme conditions.

\section{References}

[1] BOWLES, J. E.: Foundation Analysis and Design, Fifth Edition: McGraw-Hill, 1996.

[2] BRINKREVE, R. B. J.: PLAXIS 3D v 1.5 Manuals, 2005.

[3] BENCAT J., CIBUlKA, M., HRVOL, M.: Evaluation of the Soil Elastic Modules by Means of Box Tests, Communications Scientific Letters of University of Zilina, pp. 5-9, ISSN 1335-4205.

[4] DECKY, M., et. al.: Non-Destructive Determining CBR Values of Ground Structures of Engineering Constructions. J. of Intern. Scientific Publications: Ecology \& Safety. vol. 7, part 2, pp. 122-129, 2013, ISSN 1313-2563.

[5] VRABEL, B.: Report - Pile Load Test, Production Hall "F" Slovaktual Pravenec, SO 101 - Production Monoblock - pile No. A20 (in Slovak), 2014.

[6] DRUSA M.: Estimation of Strength and Deformation Characteristics of Soils (Nitra, South Slovakia) by using Cone Penetration Test, Cumhuriyet Earth Sciences J. , vol. 30, No. 2, 2013, pp. 63-70, e-ISSN:1300-1949.

[7] OBERT, L.: Final Report 462/2013. Production Hall "F" Slovaktual Pravenec. (in Slovak), 2013.

[8] MUZIK, J., SITANYIOVA, D.: Creation of 3D Geological Models using Unterpolation Methods for Nnumerical Modelling Needs, Modelling and visualization of spatial data: 19.11.2008 Bratislava: Abstracts proceedings - STU Bratislava, p. 7, 2008, ISBN 97880-227-2988-8.

[9] DECKY, M., DRUSA, M., PEPUCHA, L., ZGUTOVA, K.: Earth Structures of Transport Constructions. Harlow : Essex : Pearson, pp.180, 2013, ISBN 978-1-78399-925-5.

[10] BISWAS, S., MANNA, B.: Three Dimensional Finite Element Nonlinear Dynamic Analysis of Full-scale Piles under Vertical Excitations. Proc. of the 18 ${ }^{\text {th }}$ Intern. Conference on Soil Mechanics and Geotechnical Engineering, Paper No. 1691, 2013.

[11] DRUSA, M., MORAVCIK, M.: Foundation Structures, ISBN 978-80-554-0068-6, English textbook, EDIS : University of Zilina 2008, pp. 118. 